\title{
Bloch Surface Waves and Internal Optical Modes Driven Photonic Crystal Coupled Emission Platform for Femtomolar Detection of Aluminum Ions
}

\section{Supporting Information}

Seemesh Bhaskar, ${ }^{\not \#}$ Pratyusha Das, ${ }^{\# \#}$ Venkatesh Srinivasan, ${ }^{\dagger}$ Shivakiran Bhaktha B. N. ${ }^{* *}$ and Sai Sathish Ramamurthy ${ }^{\dagger *}$

†STAR Laboratory, Department of Chemistry, Sri Sathya Sai Institute of Higher Learning, Prasanthi Nilayam, Puttaparthi, Anantapur, Andhra Pradesh, India - 515134.

:Department of Physics, Indian Institute of Technology Kharagpur, Kharagpur, India -721302.

\#These authors contributed equally to this work.

AUTHOR INFORMATION

\section{*Corresponding Author}

* S.B.B.N.: Shivakiran Bhaktha B. N: Tel - +91-3222-283802. Email: kiranbhaktha@phy.iitkgp.ac.in *S.S.R.: Sai Sathish Ramamurthy: Tel - +91-8790314405. Email: rsaisathish@sssihl.edu.in

\section{Chemicals:}

Titanium(IV)isopropoxide (TIP) ( $\left.\mathrm{Ti}\left[\mathrm{OCH}\left(\mathrm{CH}_{3}\right)_{2}\right]_{4}\right)$, tetraethylorthosilicate (TEOS), $\mathrm{AgNO}_{3}$, Rhodamine $\mathrm{B}(\mathrm{RhB})$ and polyvinyl alcohol (PVA) [degree of hydrolysis 86-89 $\%$; molecular weight 85,000-12, 4000, g/mol] were procured from Sigma-Aldrich. All the reagents used were of analytical grade. Glassware utilized for Ag nanoparticles (AgNP) synthesis was cleaned with piranha solution (4:1 ratio of $\mathrm{H}_{2} \mathrm{SO}_{4}$ and $\mathrm{H}_{2} \mathrm{O}_{2}$ solutions respectively), and rinsed with milliQ water before use. 


\section{SPCE experimentation:}

All the experiments were performed in reverse Kreschmann (RK) configuration. Schematic S1 depicts the experimental setup used. The RhB dye was doped in different weight percentages of PVA polymer matrix and spin coated at $3000 \mathrm{rpm}$ for 60 seconds to obtain different thicknesses. ${ }^{5-11}$

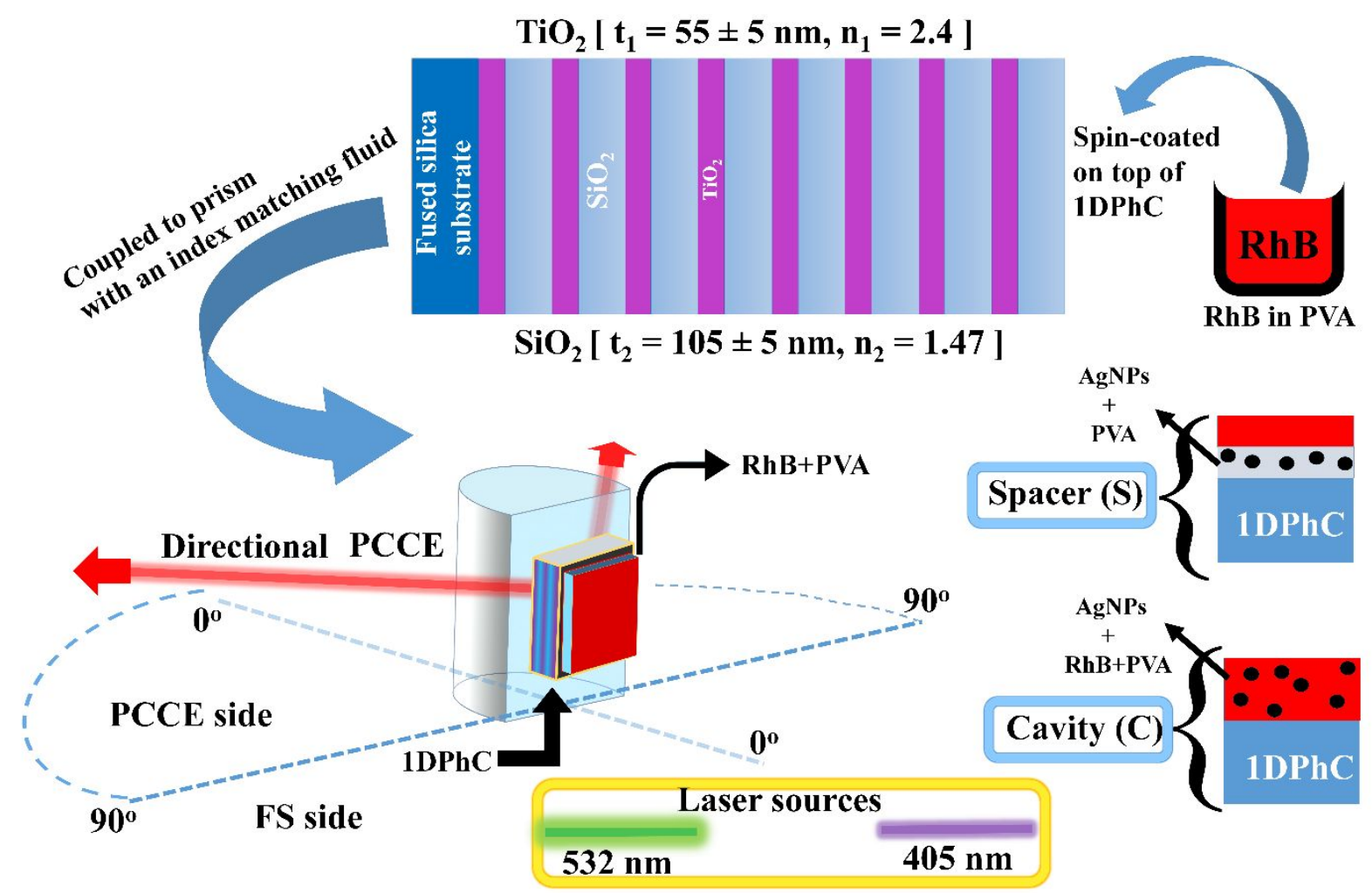

Scheme S1. Fabrication details comprising spin coating of RhB doped in PVA on 1DPhC, coupling to prism, directional PCCE and isotropic FS emission obtained using PCCE experimental setup. Bottom right: spacer and cavity interfaces along with the laser sources used for excitation of dye molecules.

The one-dimensional photonic crystal (1DPhC) is obtained by depositing eight pairs of quarter-wave thick alternating layers of titanium dioxide $\left(\mathrm{TiO}_{2}\right)$ and silica $\left(\mathrm{SiO}_{2}\right)$ on a fused silica substrate using sol gel synthesis route and dip-coating technique. Titanium(IV)isopropoxide (TIP) $\left(\mathrm{Ti}\left[\mathrm{OCH}\left(\mathrm{CH}_{3}\right)_{2}\right]_{4}\right)$ was used as $\mathrm{TiO}_{2}$ sol precursor. Isopropyl alcohol (IPA, $\left.\left(\mathrm{CH}_{3}\right)_{2} \mathrm{CHOH}\right)$ was added to TIP solution and stirred at $70^{\circ} \mathrm{C}$ for 30 minutes. Then acetic acid $\left(\mathrm{C}_{2} \mathrm{H}_{4} \mathrm{O}_{2}\right)$ was added to the mixture as a chelating agent and stirred for $1 \mathrm{~h}$ at $70^{\circ} \mathrm{C}$. After an hour, methanol (MeOH) was added to the solution and stirred at $70^{\circ} \mathrm{C}$ for 30 minutes, to 
obtain a transparent solution. The TIP: IPA: acetic acid: MeOH molar ratio was 1:11:17:55. The sol for silica layer was obtained by mixing tetraethylorthosilicate (TEOS), ethanol (EtOH), deionised water $\left(\mathrm{DI} \mathrm{H}_{2} \mathrm{O}\right)$, and hydrochloric acid $(\mathrm{HCl})$ as a catalyst. The TEOS:HCl:EtOH: $\mathrm{H}_{2} \mathrm{O}$ molar ratio was 1:0.01:25:2. It was then stirred for $1 \mathrm{~h}$ at $65^{\circ} \mathrm{C}$. Both the solutions were filtered with the help of $0.2 \mu \mathrm{m}$ Whatman Puradisc syringe filters prior to coating on the substrate. The thin films were alternatively dip-coated on fused silica substrate at a dipping rate of $1000 \mu \mathrm{m} \mathrm{s}^{-1}$. Each layer was annealed in air, at $900^{\circ} \mathrm{C}$ for 1 minute, prior to the next coating.

The spacer and cavity configurations are explained in detail in our earlier publications. ${ }^{9-11,37,52}$ In brief, spacer configuration consists of spin coating a nanolayer of PVA doped appropriate NPs on top of $1 \mathrm{DPhC}$, followed by spin coating nanolayer of dye doped PVA. Therefore, the NPs in the first nanolayer acts as a spacer material between the radiating dipoles and the $1 \mathrm{DPhC}$. Cavity configuration consists of spin coating a mixture of NPs and radiating dipoles on top of the $1 \mathrm{DPhC}$ as a single layer. The emitter dipoles sandwiched in the nanogaps between the $1 \mathrm{DPhC}$ and NPs experience high electromagnetic (EM) field confinement (termed hot-spots) in that cavity environment. Both the spacer and cavity configurations are shown in the schematic S1 (right bottom). Blanks for spacer and cavity are obtained by maintaining the same spin coating method, but without the presence of any nanoparticles (NPs).

\section{Synthesis and characterization of AgNPs:}

The silver nanoparticles (AgNPs) were synthesized via the well-established sodium citrate reduction method. ${ }^{1-3,40}$ In brief, $1 \mathrm{mM}$ concentration of $\mathrm{AgNO}_{3}$ was taken in appropriate volume and heated with continuous stirring till the solution began to boil. The temperature of the container was continuously monitored by dipping a clean thermometer into the solution. As soon as the solution began to boil, sodium citrate (1 wt \%) was added drop wise till a pale yellow coloration was evident. Subsequently, the container was removed from the heating element and was kept at room temperature with continued stirring. Once the solution reached room temperature, a small volume $(3 \mathrm{ml})$ was used to check the absorbance profile of AgNPs. It showed a sharp maximum absorbance at $432 \mathrm{~nm}$ indicating the SPR band of obtained AgNPs. The morphology of the nanoparticles was confirmed with the high resolution transmission electron microscope (HRTEM) characterization [JEM-2100Plus Transmission Electron 
Microscope]. The HRTEM image, d-spacing [, and discussion pertaining to this has been presented in Figure 1 of the main manuscript.

\section{Results and discussion:}

Photonic crystal coupled emission experiments for $30 \mathrm{~nm}, 60 \mathrm{~nm}, 90 \mathrm{~nm}$ and $120 \mathrm{~nm}$ PVA thicknesses and laser studies (not explained in main manuscript), are presented here. The angular sweep for every case was performed from $0^{\circ}$ to $90^{\circ}$ in steps of two degrees in the distal part of the prism. And at places where uncommon behavior was encountered such as appearance of doublet peak emission, the emission was recorded at $1^{\circ}$ resolution.
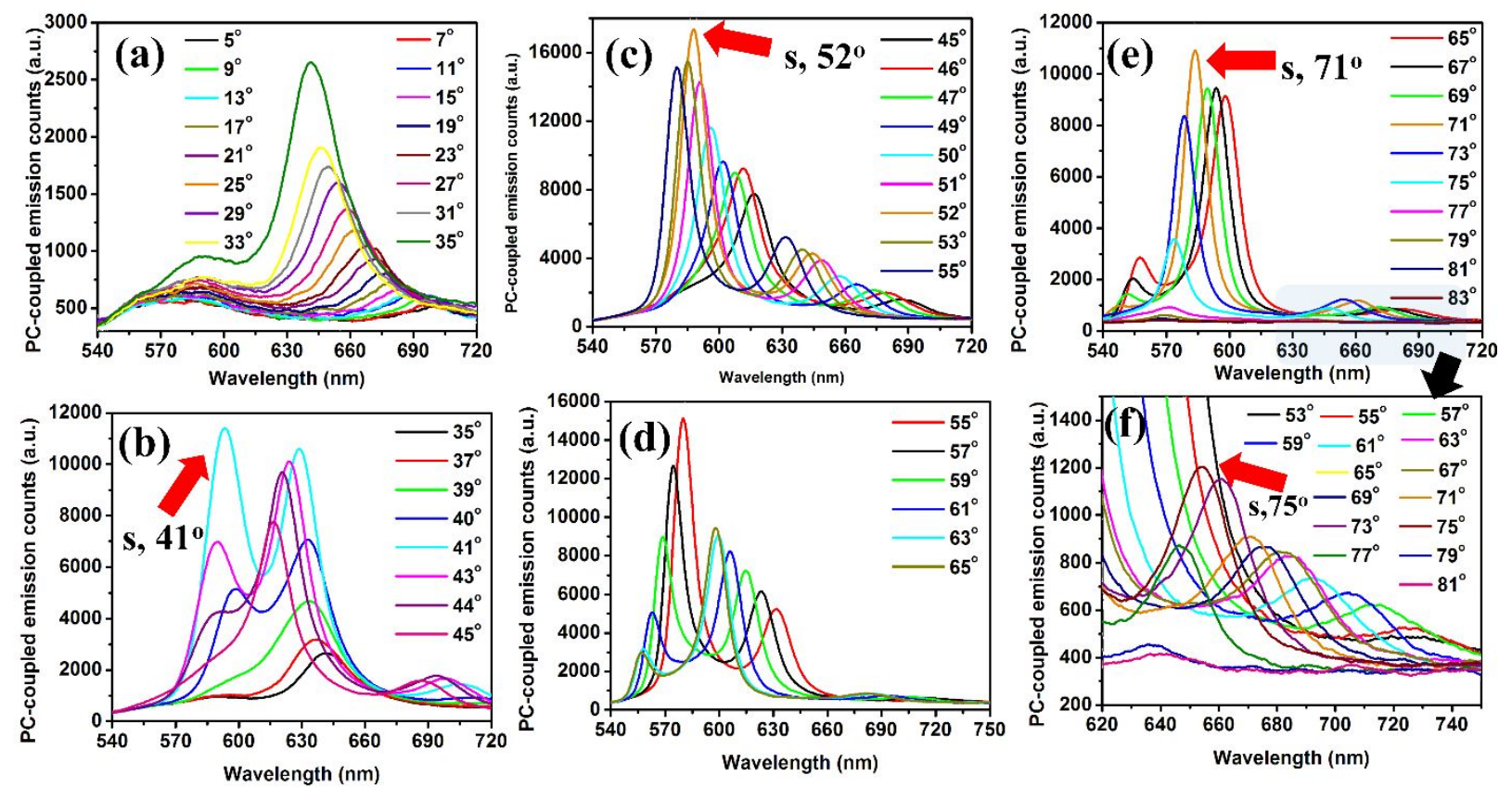

Figure S1. PCCE counts for angles (a) $55^{\circ}-35^{\circ}$, (b) $35^{\circ}-45^{\circ}$, (c) $45^{\circ}-55^{\circ}$, (d) $55^{\circ}-65^{\circ}$, (e) $65^{\circ}-83^{\circ}$, (f) $53^{\circ}-$ $81^{\circ}$, with red arrows indicating the PCCE angle having maximum fluorescence intensity counts. These spectra are for $532 \mathrm{~nm}$ laser excitation and $30 \mathrm{~nm}$ PVA dielectric. (f) Enlarged section of emission patterns for larger detection angles in RK configuration.

\section{Explanation pertaining to Figure S1:}

The dispersion diagrams presented in the main manuscript contains all the information about the variation in angle and wavelength along with the PCCE intensity counts (both numerical and 
experimental). In order to further impress upon the intricate details of these dispersion plots this section gives explanation of the experimental results for RhB doped in $30 \mathrm{~nm}$ PVA dielectric, emission spectrum from $1 \mathrm{DPhC}$ was recorded at every two degrees. As can be seen in from Figure S1, it has been divided into 6 angular ranges, Figures S1 a-f. Figure S1a portrays an important outcome on the effect of PBG, where the intensity counts increases at higher wavelengths as the angle of detection in RK configuration is moved away from the normal towards the critical angle. Although the emission maxima for $\mathrm{RhB}$ is in the range 580-590 $\mathrm{nm}$, for normal collection $\left(0^{\circ}\right)$ this becomes forbidden due to the existence of PBG supported by the stratified multi-stack.

It is seen that the emission intensity of the first mode [mode A] (at $597 \mathrm{~nm}$ ) originates at lower angle $\left(40^{\circ}\right)$, develops maximum intensity (at $593 \mathrm{~nm}$ ) at $41^{\circ}$ and then merges into the second mode [mode B] $(590 \mathrm{~nm})$ at a slightly higher angle $\left(43^{\circ}\right)$, as shown in Figure S1b. Similarly, the second (B), third (C) and fourth (D) modes at angles and wavelength ranges from $11^{\circ}-69^{\circ}, 697-550 \mathrm{~nm} ; 37^{\circ}-77^{\circ}, 718-569 \mathrm{~nm} ; 61^{\circ}-77^{\circ}, 700-632 \mathrm{~nm}$ are presented in Figure S1c, S1e, and S1f. It is to be noted that though a strong spectral overlap is observed for the initial two modes, the latter two are better resolved. The red arrows in all the figures indicate the angle of maximum PCCE. One can also notice that in the regions where important angular dependence behavior is observed, at the angle of maximum emission intensity involving the appearance of doublets, the emission was recorded at $1^{\circ}$ resolution for capturing all of the spectral signatures. 

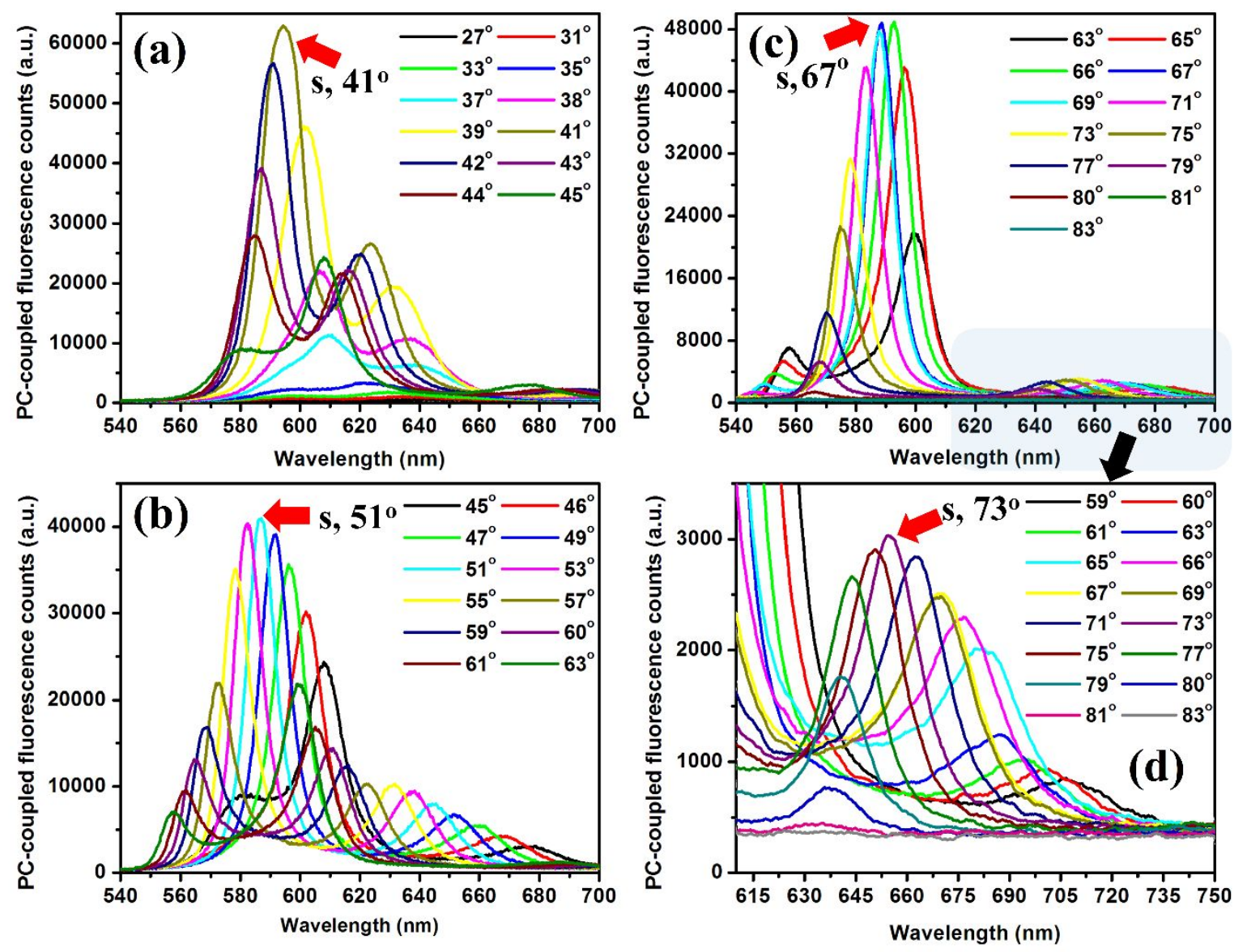

Figure S2. PCCE counts for angles (a) $27^{\circ}-45^{\circ}$, (b) $45^{\circ}-63^{\circ}$, (c) $63^{\circ}-81^{\circ}$, (d) $59^{\circ}-83^{\circ}$, with red arrows indicating the PCCE angle having maximum fluorescence intensity counts obtained using $\mathbf{5 3 2} \mathbf{n m}$ laser excitation and $60 \mathrm{~nm}$ PVA dielectric. (d) Enlarged section of emission patterns for larger detection angles in RK configuration.

\section{Explanation pertaining to Figure S2:}

The PCCE intensity spectra at different angles showing varied emission patterns for radiating dipoles doped in $60 \mathrm{~nm}$ PVA and $532 \mathrm{~nm}$ laser excitation are given in Figure S2. An increased thickness of the dielectric offers a conducive environment for augmented emission intensity and coherent coupling from greater number of emitter dipoles. The photonic crystal design accomplished in the current study modulates the basic dispersion patterns of $1 \mathrm{DPhC}$ that becomes more prominent for larger thicknesses of PVA dielectric and is discussed in detail in the 
main manuscript. In Figure S2, we clearly notice four modes that can be evidently distinguished depending on the angle at which the corresponding emission is observed. The first mode shows a maximum intensity at lower angle $\left(41^{\circ}\right)$ and is confined in the range of angles: $27^{\circ}-45^{\circ}$ and wavelength spanning from $644-579 \mathrm{~nm}$. As discussed in the main manuscript, this mode is interpreted as BSWs on account of EM surface states sustained by them. In addition to this, the maximum emission intensities for the three modes (B, C and D) are seen at angles and wavelength ranges from: $45^{\circ}-63^{\circ}, 638-541 \mathrm{~nm} ; 63^{\circ}-81^{\circ}, 715-559 \mathrm{~nm} ; 59^{\circ}-83^{\circ}, 705-559 \mathrm{~nm}$ (Figure S2b, S2c, S2d) and is related to IOMs. Similar PCCE fluorescence intensity spectra obtained using $532 \mathrm{~nm}$ and $405 \mathrm{~nm}$ laser excitation sources for other thicknesses of dye doped dielectric has been presented in the subsequent section of the supporting information and the discussions remain the same.
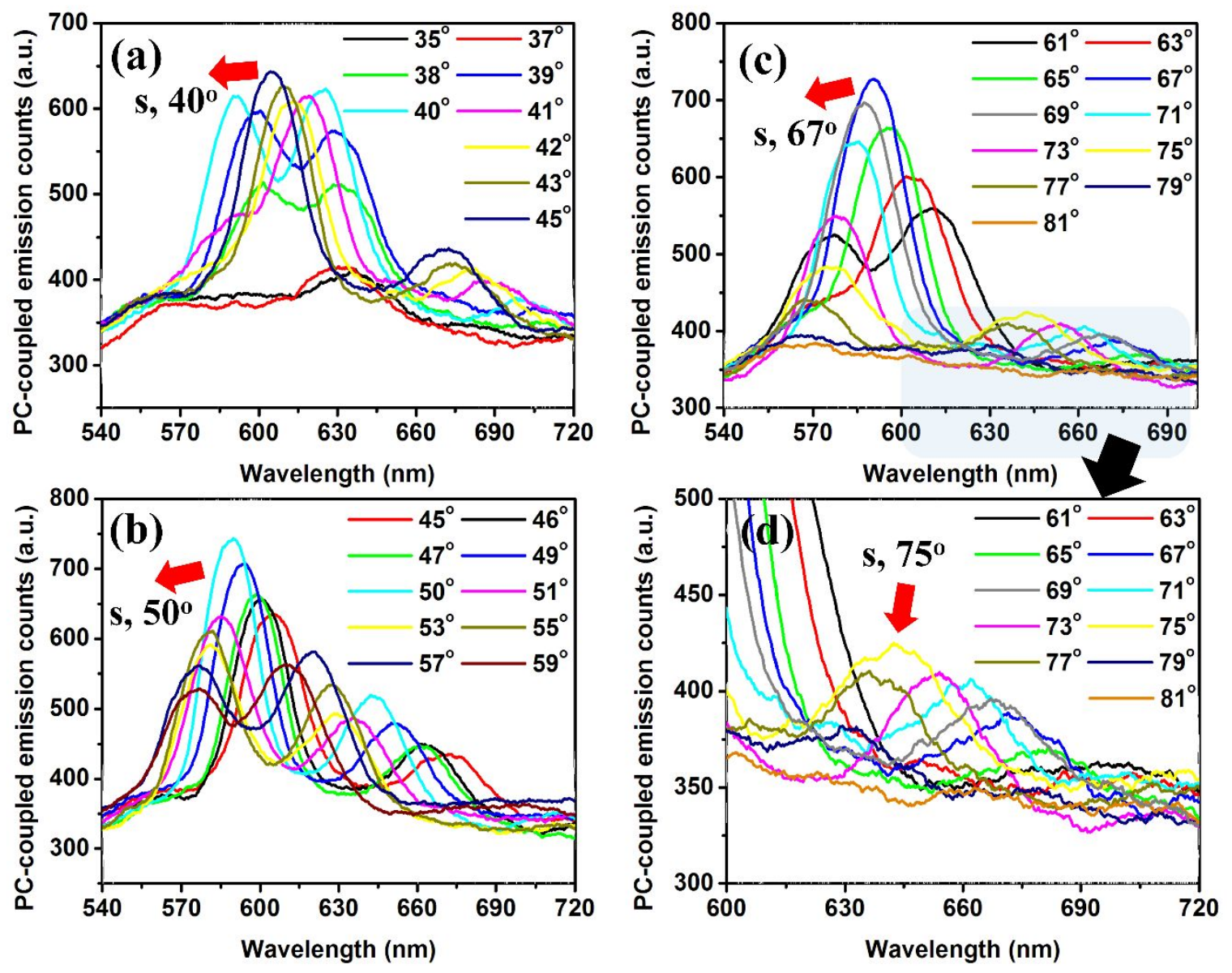
Figure S3. PCCE counts for angles (a) $35^{\circ}-45^{\circ}$, (b) $45^{\circ}-59^{\circ}$, (c) $61^{\circ}-81^{\circ}$, (d) $61^{\circ}-81^{\circ}$, with red arrows indicating the PCCE angle having maximum fluorescence intensity counts, for $405 \mathbf{n m}$ laser excitation and $30 \mathrm{~nm} \boldsymbol{P V A}$ dielectric. (d) Enlarged section of emission patterns for larger detection angles in RK configuration. A resolution of $2^{\circ}$ was maintained for the angular sweep from $0^{\circ}$ to $90^{\circ}$.
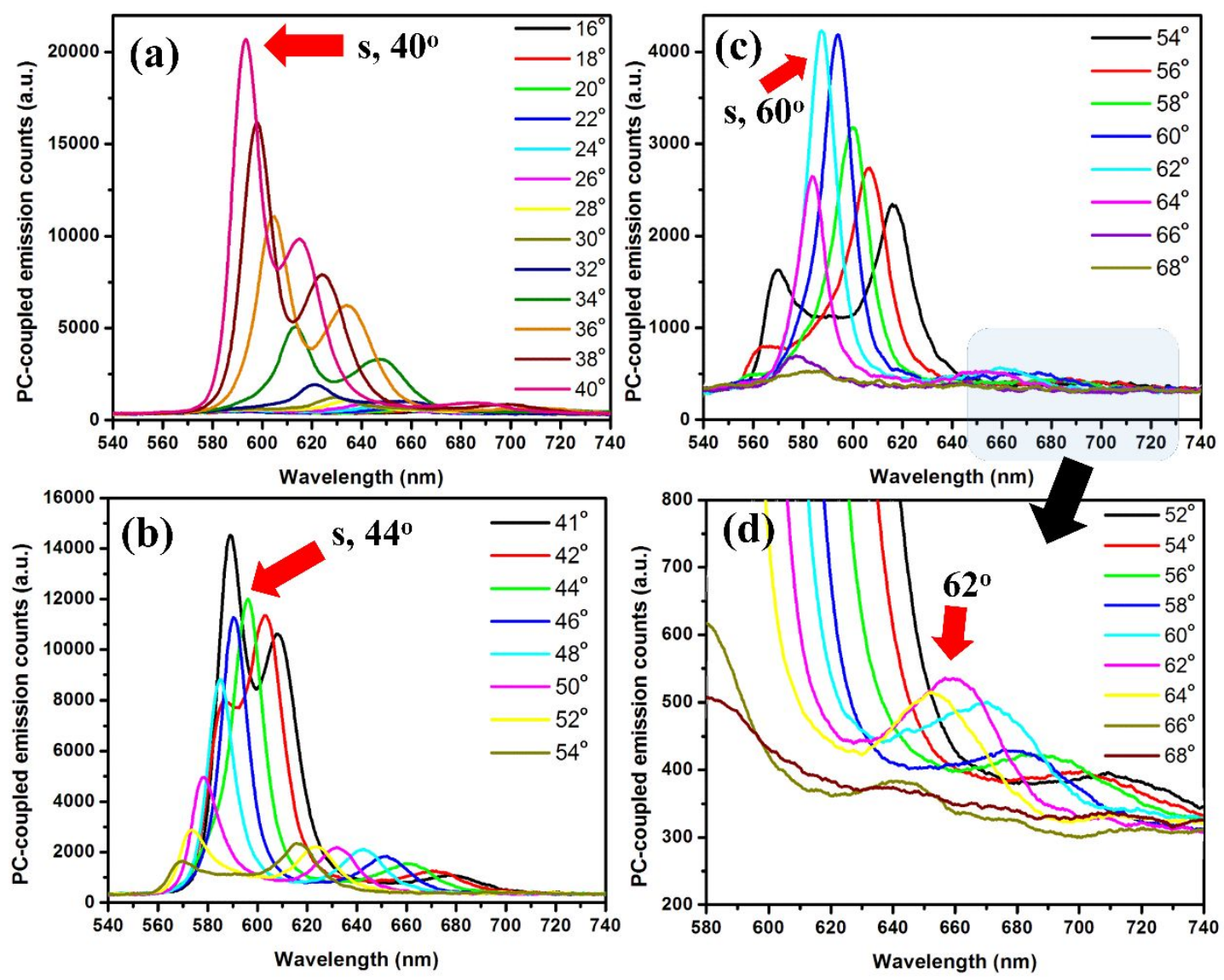

Figure S4. PCCE counts for angles (a) $16^{\circ}-40^{\circ}$, (b) $41^{\circ}-54^{\circ}$, (c) $54^{\circ}-68^{\circ}$, (d) $52^{\circ}-68^{\circ}$, with red arrows indicating the PCCE angle having maximum fluorescence intensity counts, for $405 \mathbf{n m}$ laser excitation and $60 \mathrm{~nm} \boldsymbol{P V A}$ dielectric. (d) Enlarged section of emission patterns for larger detection angles in RK configuration. A resolution of $2^{\circ}$ was maintained for the angular sweep from $0^{\circ}$ to $90^{\circ}$. 

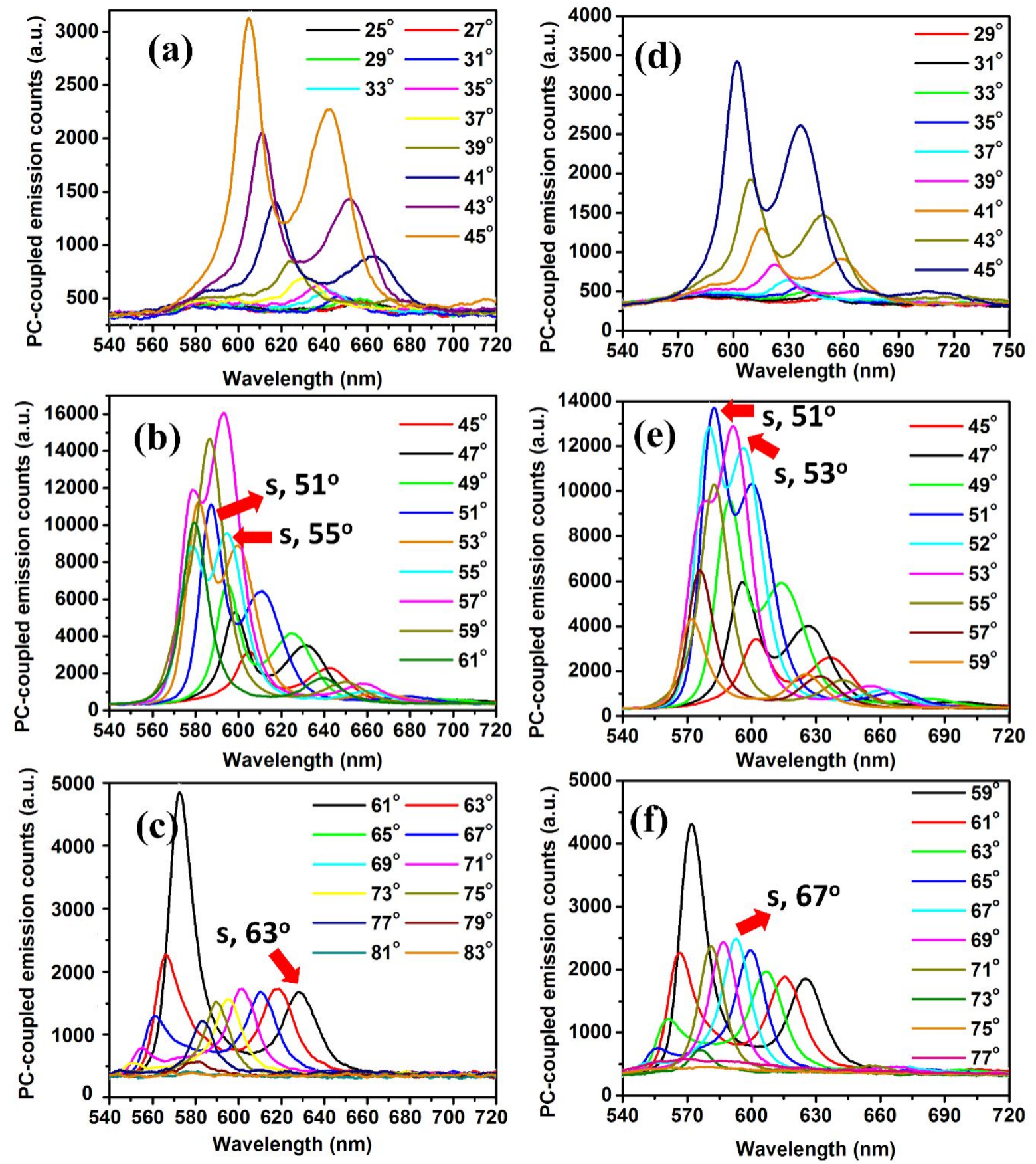

Figure S5. PCCE intensity spectra for angles (a) $25^{\circ}-45^{\circ}$, (b) $45^{\circ}-61^{\circ}$, (c) $61^{\circ}-83^{\circ}$ for $532 \mathbf{~ n m}$ laser excitation. (d) $29^{\circ}-45^{\circ}$, (e) $45^{\circ}-59^{\circ}$, (f) $59^{\circ}-77^{\circ}$ for $405 \mathrm{~nm}$ laser excitation with red arrows indicating the PCCE angle having maximum fluorescence intensity counts. A resolution of $2^{\circ}$ 
was maintained for the angular sweep from $0^{\circ}$ to $90^{\circ}$. All the PCCE spectra are pertaining to 90 $\boldsymbol{n m}$ thick $\boldsymbol{P V A}$ dielectric doped with radiating dipoles.
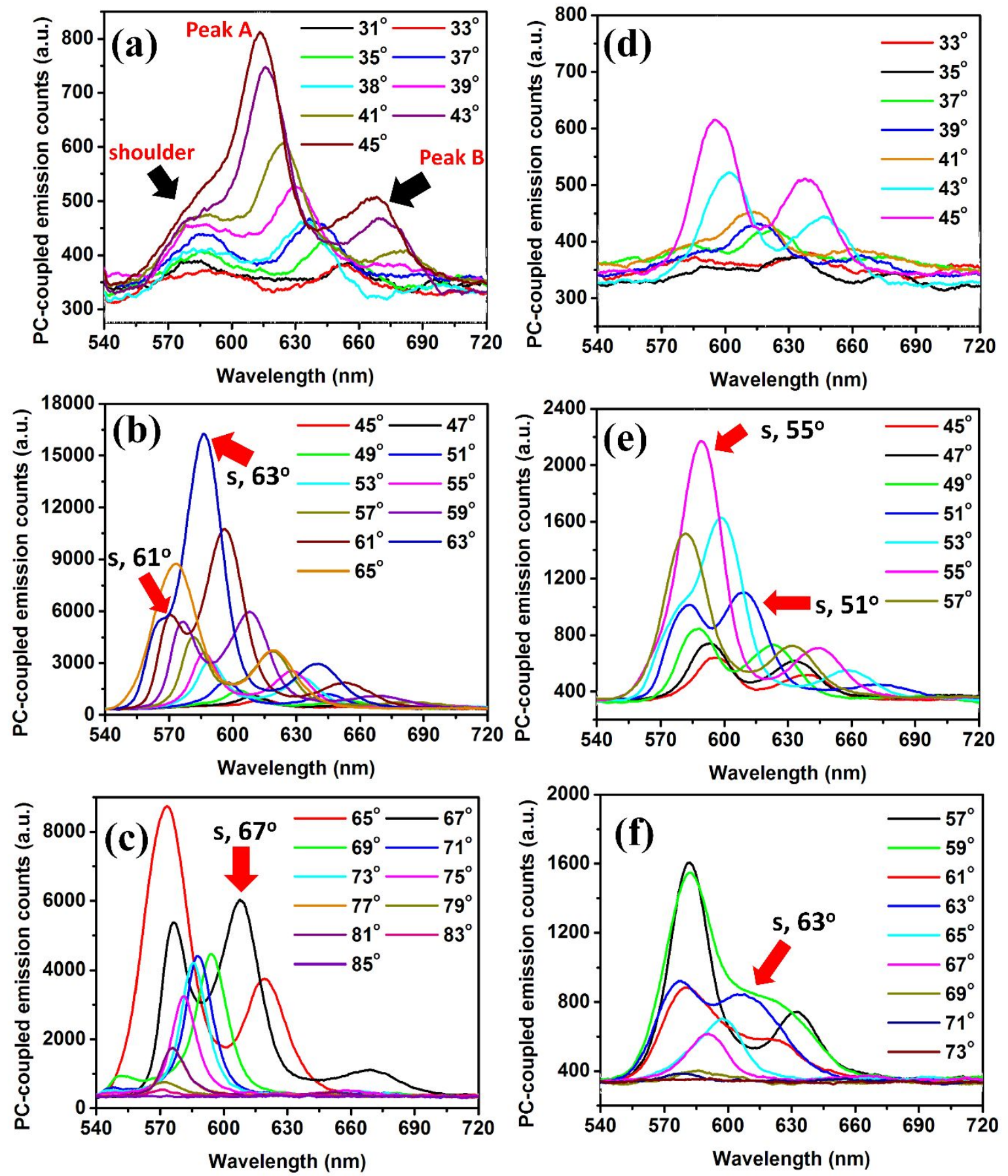
Figure S6.PCCE intensity spectra for angles (a) $31^{\circ}-45^{\circ}$, (b) $45^{\circ}-65^{\circ}$, (c) $65^{\circ}-83^{\circ}$ for $532 \mathrm{~nm}$ laser excitation. (d) $33^{\circ}-45^{\circ}$, (e) $45^{\circ}-57^{\circ}$, (f) $57^{\circ}-73^{\circ}$ for $405 \mathrm{~nm}$ laser excitation with red arrows indicating the PCCE angle having maximum fluorescence intensity counts. A resolution of $2^{\circ}$ was maintained for the angular sweep from $0^{\circ}$ to $90^{\circ}$. All the PCCE spectra are pertaining to 120 nm thick $\boldsymbol{P V A}$ dielectric doped with radiating dipoles.

Table S1. Comparative study of PCCE enhancements obtained using different thicknesses of PVA dielectric and laser excitation. The nomenclature used to describe and compare the modes encountered in a dielectric of a particular thickness are: Very strong (VS), Strong (S), High (H), Moderate (M), Weak (W) and Very weak (VW).

\begin{tabular}{|c|c|c|c|c|}
\hline Laser & \multicolumn{2}{|c|}{$\begin{array}{l}532 \mathrm{~nm} \text { (green) excitation } \\
\text { Angle, [Range of Angles] } \\
\text { Wavelength range encountered; Fluorescence } \\
\text { enhancements }\end{array}$} & \multicolumn{2}{|c|}{$\begin{array}{l}405 \mathrm{~nm} \text { (violet) excitation } \\
\text { Angle, [Range of Angles] } \\
\text { Wavelength range encountered; Fluorescence } \\
\text { enhancements, \% of s-polarization }\end{array}$} \\
\hline Mode A, 30nm & $\begin{array}{l}\mathbf{4 1}^{\mathbf{0}} ;\left[40^{\circ}-43^{\circ}\right] \\
597-590 \mathrm{~nm} ; \mathbf{1 5}\end{array}$ & H, similar to peak $B$ & $\begin{array}{l}\mathbf{4 0}^{\mathbf{o}} ;\left[35^{\circ}-41^{\circ}\right] \\
626-587 \mathrm{~nm} ; \mathbf{2}\end{array}$ & $\begin{array}{l}\text { W; appears like a } \\
\text { doublet. }\end{array}$ \\
\hline Mode B, 30nm & $\begin{array}{l}\mathbf{5 2}^{\mathbf{0}} ;\left[11^{\mathrm{o}}-71^{\circ}\right] \\
697-550 \mathrm{~nm} ; \mathbf{2 2}\end{array}$ & $\begin{array}{l}\text { S, appears like } \\
\text { doublet. }\end{array}$ & $\begin{array}{l}\mathbf{5 0}^{\circ} ;\left[39^{\circ}-63^{\circ}\right] \\
633-566 \mathrm{~nm} ; \mathbf{3}\end{array}$ & $\mathbf{W}$ \\
\hline Mode C, 30nm & $\begin{array}{l}\mathbf{7 1}^{\mathbf{0}} ;\left[38^{\circ}-77^{\circ}\right] \\
718-569 \mathrm{~nm} ; \mathbf{1 3}\end{array}$ & $\mathbf{M}$ & $\begin{array}{l}\mathbf{6 5}^{\circ} ;\left[40^{\circ}-79^{\circ}\right] \\
710-560 \mathrm{~nm} ; \mathbf{2 . 7}\end{array}$ & $\mathbf{W}$ \\
\hline Mode D, 30nm & $\begin{array}{l}\mathbf{7 5}^{\mathbf{0}} ;\left[61^{\mathrm{o}}-77^{\circ}\right] \\
700-632 \mathrm{~nm} ; 2\end{array}$ & VW & $\begin{array}{l}\mathbf{7 5}^{\mathbf{0}} ;\left[63^{\circ}-79^{\circ}\right] \\
689-603 \mathrm{~nm} ; \mathbf{2}\end{array}$ & $\mathbf{V W}$ \\
\hline Mode A, 60nm & $\begin{array}{l}\mathbf{4 1}^{\mathbf{0}} ;\left[25^{\circ}-45^{\circ}\right] \\
644-579 \mathrm{~nm} ; 35\end{array}$ & VS & $\begin{array}{l}\mathbf{4 4}^{\mathbf{0}} ;\left[21^{\circ}-47^{\circ}\right] \\
670-586 \mathrm{~nm} ; \mathbf{3 6}\end{array}$ & VS \\
\hline Mode B, 60nm & $\begin{array}{l}\mathbf{5 1}^{\mathbf{0}} ;\left[37^{\circ}-75^{\circ}\right] \\
638-541 \mathrm{~nm} ; \mathbf{2 4}\end{array}$ & $\mathbf{M}$ & $\begin{array}{l}\mathbf{4 9}^{\mathbf{0}} ;\left[37^{\circ}-63^{\circ}\right] \\
653-565 \mathrm{~nm} ; \mathbf{2 0}\end{array}$ & $\mathbf{H}$ \\
\hline Mode C, 60nm & $\begin{array}{l}\mathbf{6 7}^{\mathbf{0}} ;\left[35^{\circ}-83^{\circ}\right] \\
715-559 \mathrm{~nm} ; \mathbf{2 8}\end{array}$ & $\mathbf{S}$ & $\begin{array}{l}\mathbf{6 7}^{\mathbf{0}} ;\left[39^{\circ}-71^{\circ}\right] \\
726-578 \mathrm{~nm} ; \mathbf{8}\end{array}$ & $\mathbf{W}$ \\
\hline Mode D, 60nm & $\begin{array}{l}\mathbf{7 3}^{\mathbf{0}} ;\left[47^{\circ}-83^{\circ}\right] \\
705-559 \mathrm{~nm} ; \mathbf{2 3}\end{array}$ & $\mathbf{M}$ & $\begin{array}{l}\mathbf{6 7}^{\mathbf{0}} ;\left[57^{\circ}-71^{\circ}\right] \\
712-644 \mathrm{~nm} ; \mathbf{2}\end{array}$ & VW \\
\hline Mode A, 90nm & $\begin{array}{l}\mathbf{5 1}^{\mathbf{0}} ;\left[25^{\circ}-57^{\circ}\right] \\
601-582 \mathrm{~nm} ; \mathbf{2 9}\end{array}$ & $\mathbf{H}$ & $\begin{array}{l}\mathbf{5 1}^{\mathbf{0}} ;\left[29^{\circ}-53^{\circ}\right] \\
654-577 \mathrm{~nm} ; \mathbf{2 8}\end{array}$ & S; doublet \\
\hline Mode B, 90nm & $\begin{array}{l}\mathbf{5 5}^{\mathbf{0}} ;\left[39^{\circ}-73^{\circ}\right] \\
669-543 \mathrm{~nm} ; \mathbf{4 4}\end{array}$ & VS & $\begin{array}{l}\mathbf{5 3}^{\circ} ;\left[37^{\circ}-67^{\circ}\right] \\
683-551 \mathrm{~nm} ; \mathbf{2 5}\end{array}$ & M \\
\hline Mode C, 90nm & $\begin{array}{l}\mathbf{6 7}^{\mathbf{0}} ;\left[39^{\circ}-78^{\circ}\right] \\
728-569 \mathrm{~nm} ; \mathbf{5}\end{array}$ & $\mathbf{W}$ & $\begin{array}{l}\mathbf{6 7}^{\mathbf{0}} ;\left[43^{\circ}-7^{\circ}\right] \\
732-563 \mathrm{~nm} ; \mathbf{5}\end{array}$ & VW \\
\hline Mode D, 90nm & Not seen/very week & --------- & Not seen/very week & ------- \\
\hline
\end{tabular}




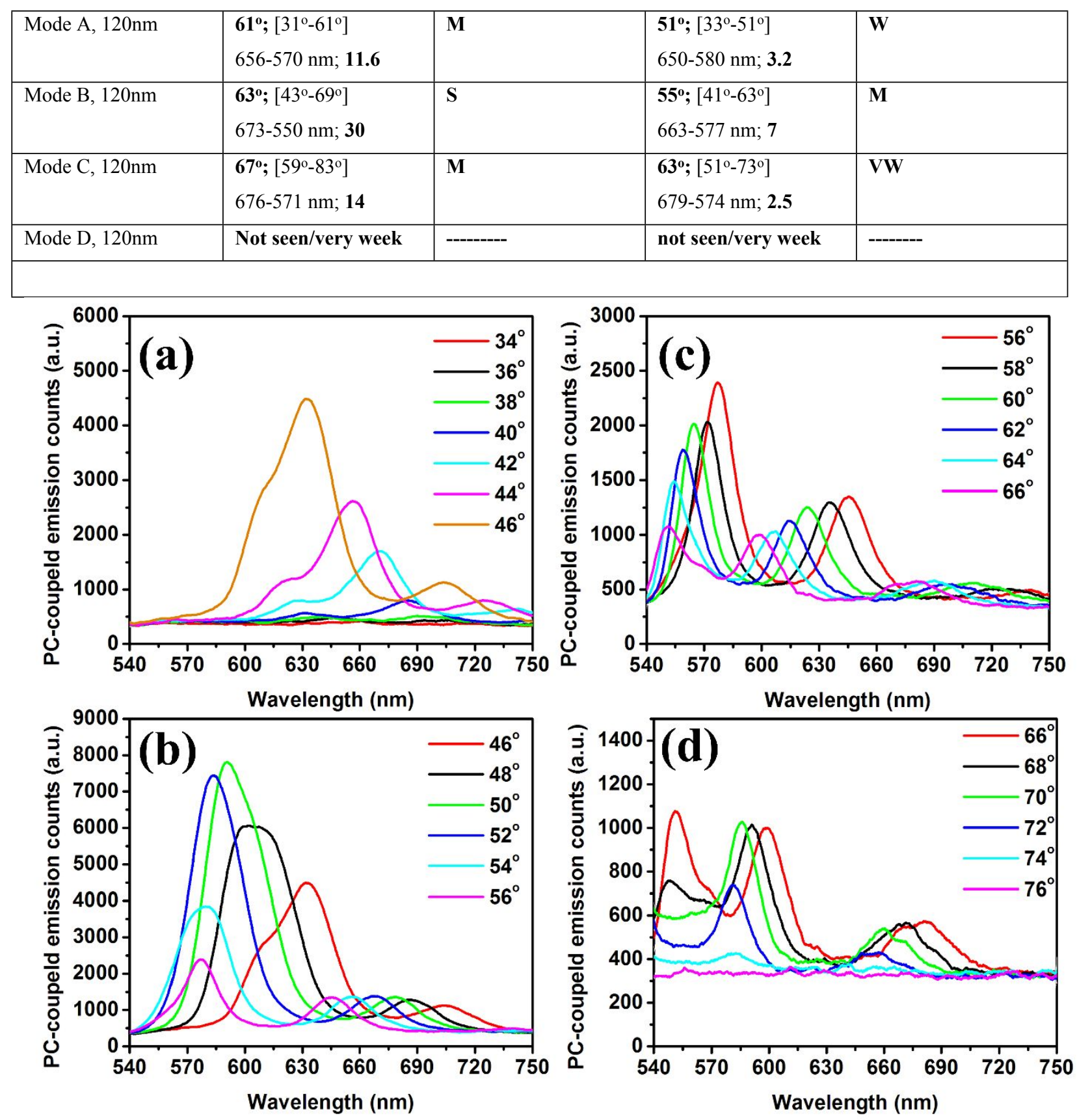

Figure S7. PCCE counts for angles (a) $34^{\circ}-46^{\circ}$, (b) $46^{\circ}-56^{\circ}$, (c) $56^{\circ}-66^{\circ}$, (d) $66^{\circ}-76^{\circ}$, for $532 \mathrm{~nm}$ laser excitation and $60 \mathrm{~nm}$ PVA dielectric doped with ImM ARS and AgNPs in cavity configuration. All the experiments were performed in $R K$ configuration. A resolution of $2^{\circ}$ was maintained for the angular sweep from $0^{\circ}$ to $90^{\circ}$. 

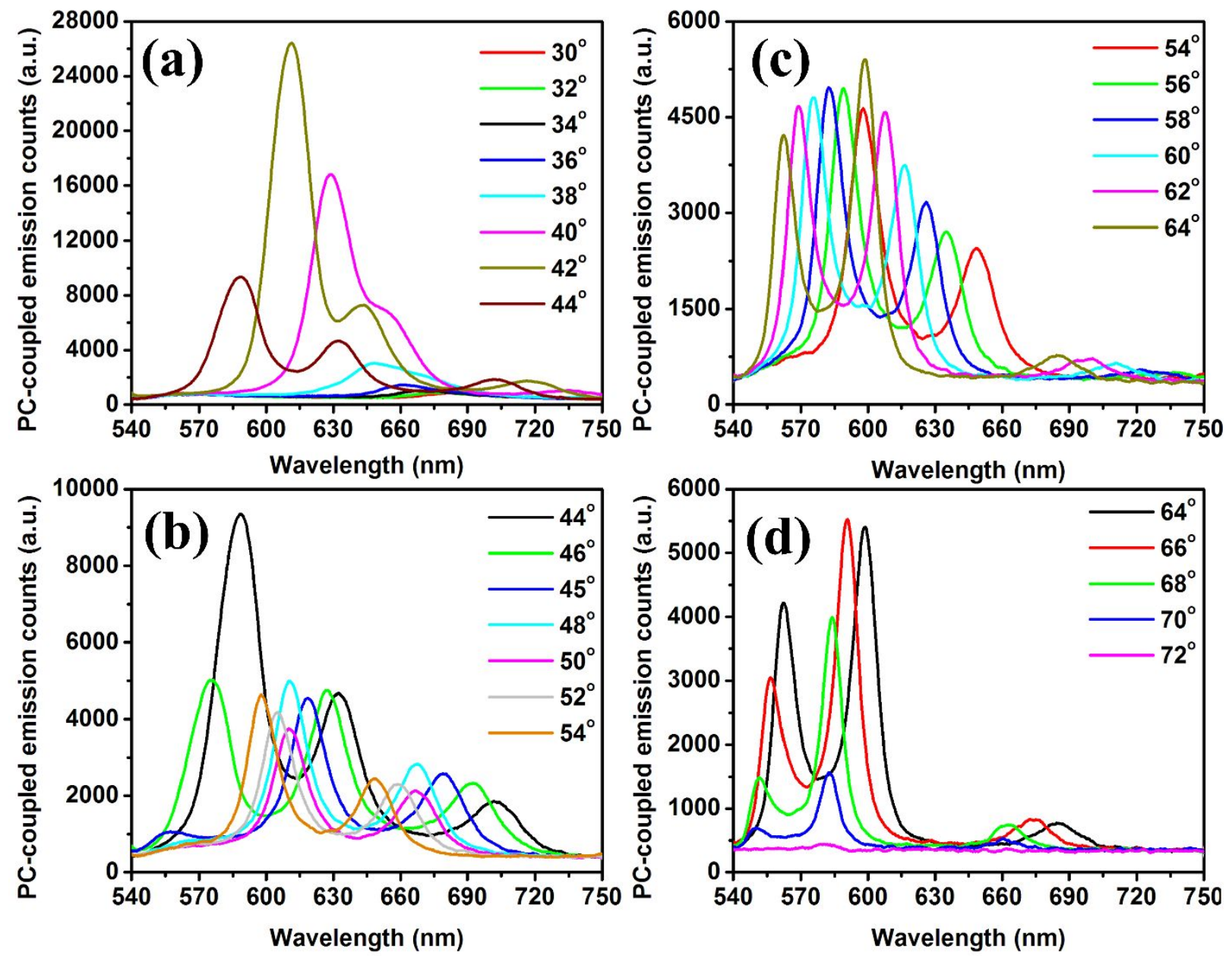

Figure S8. PCCE counts for angles (a) $30^{\circ}-44^{\circ}$, (b) $44^{\circ}-54^{\circ}$, (c) $54^{\circ}-64^{\circ}$, (d) $64^{\circ}-72^{\circ}$, for $532 \mathrm{~nm}$ laser excitation and $60 \mathrm{~nm}$ PVA dielectric doped with $1 \mathrm{mM} A R S, 1 \mathrm{mM} A l^{3+}$ ions (without AgNPS). All the experiments were performed in $R K$ configuration. A resolution of $2^{\circ}$ was maintained for the angular sweep from $0^{\circ}$ to $90^{\circ}$. 

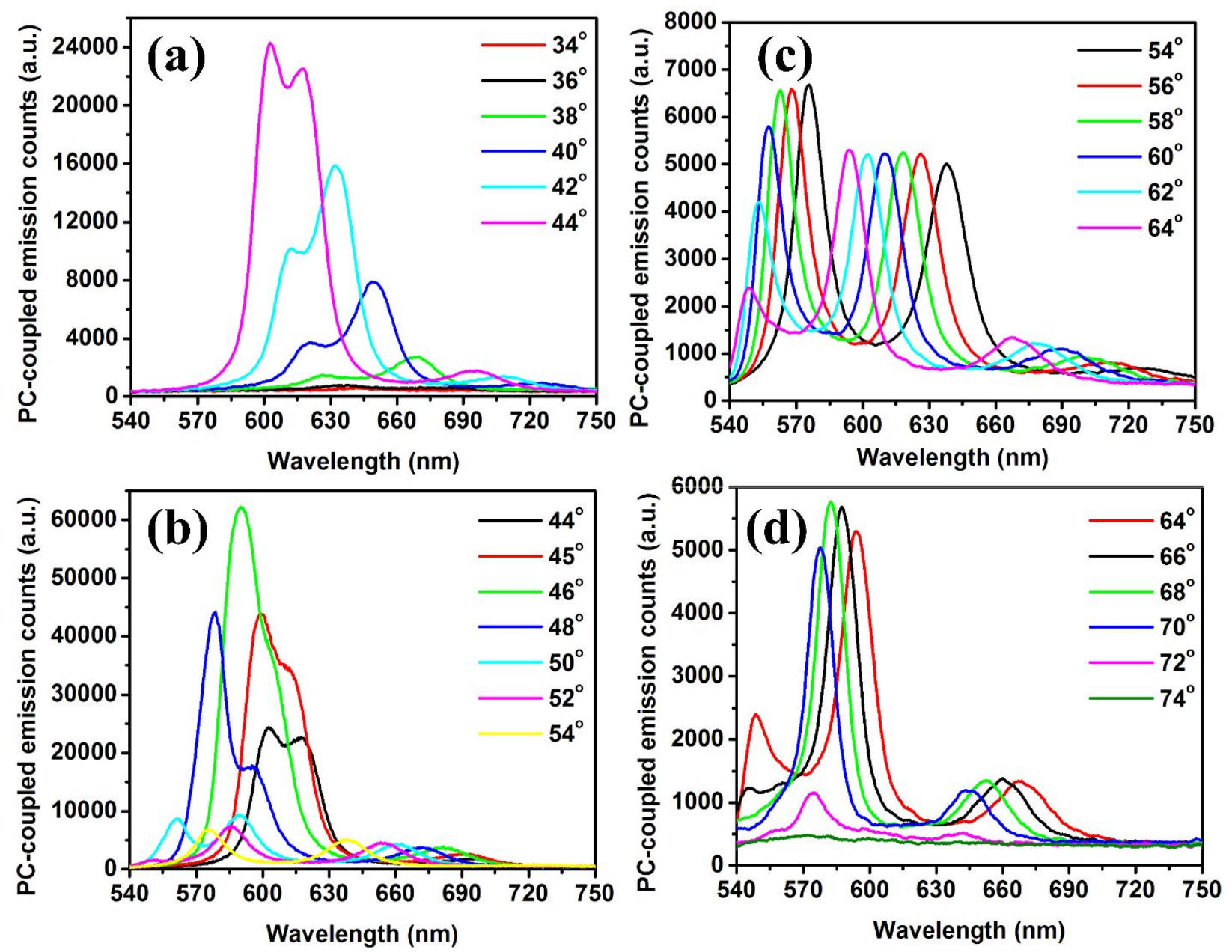

Figure S9. PCCE counts for angles (a) $34^{\circ}-44^{\circ}$, (b) $44^{\circ}-54^{\circ}$, (c) $54^{\circ}-64^{\circ}$, (d) $64^{\circ}-72^{\circ}$, for 532 nm laser

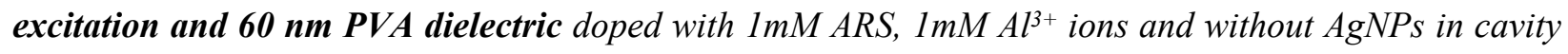
configuration. All the experiments were performed in $R K$ configuration. A resolution of $2^{\circ}$ was maintained for the angular sweep from $0^{\circ}$ to $90^{\circ}$. 

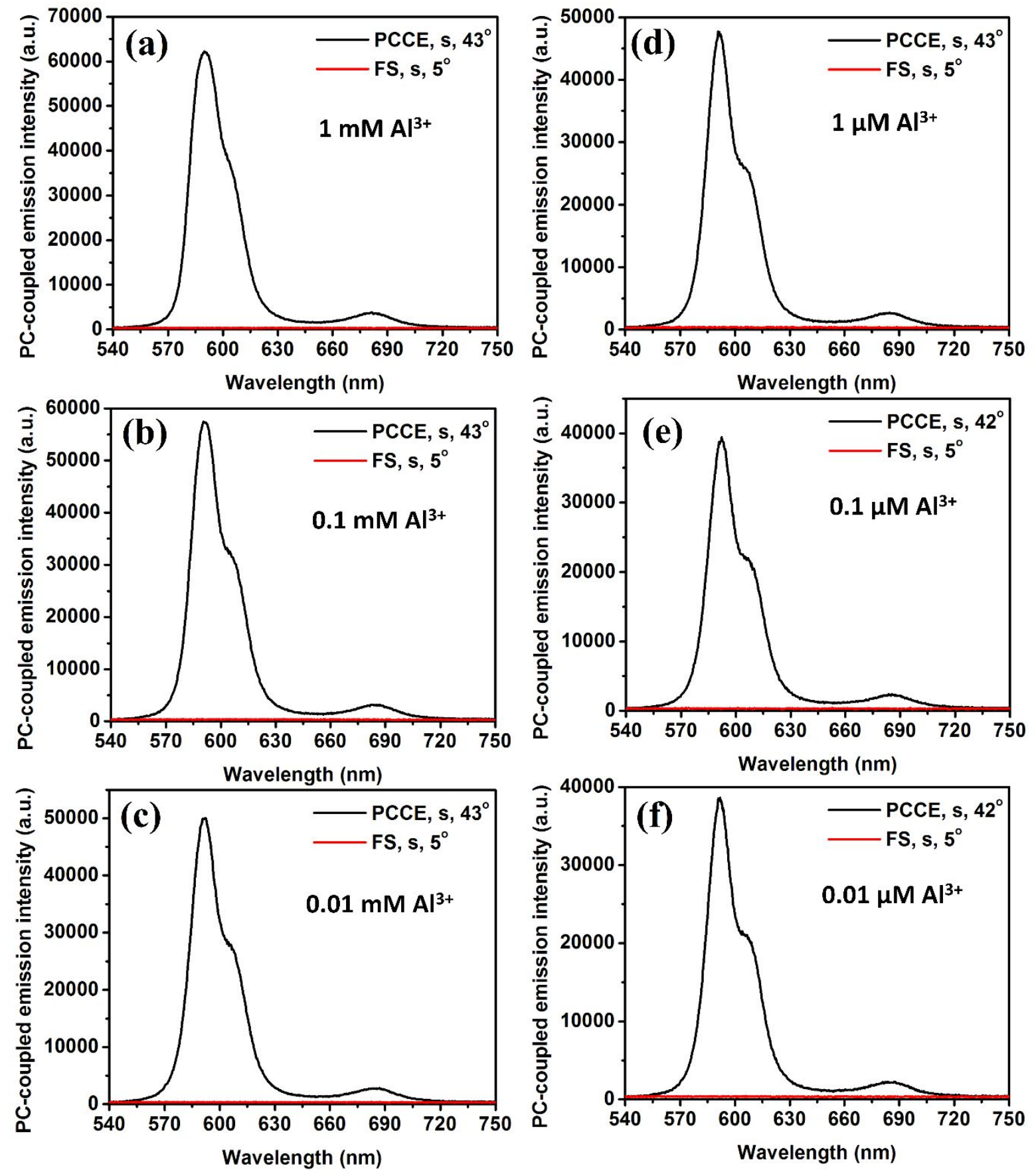

Figure S10. PCCE spectra for (a) $1 \mathrm{mM}$, (b) $0.1 \mathrm{mM}$, (c) $0.01 \mathrm{mM}$, (d) $1 \mu \mathrm{M}$, (e) $0.1 \mu \mathrm{M}$ and (f) $0.01 \mu \mathrm{M}$ concentrations of $A l^{3+}$ ions with $1 \mathrm{mM} A R S$ and AgNPs. Experiments were performed with $\mathbf{5 3 2} \mathbf{n m}$ laser excitation and $60 \mathrm{~nm} P \boldsymbol{P A}$ dielectric in cavity configuration. The plots indicate the PCCE spectra along with their respective FS spectra. The collection angles are also mentioned. In the angular sweep from $0^{\circ}$ 
to $90^{\circ}$ degrees, the angle showing maximum emission intensity counts is chosen for each of the cases above.
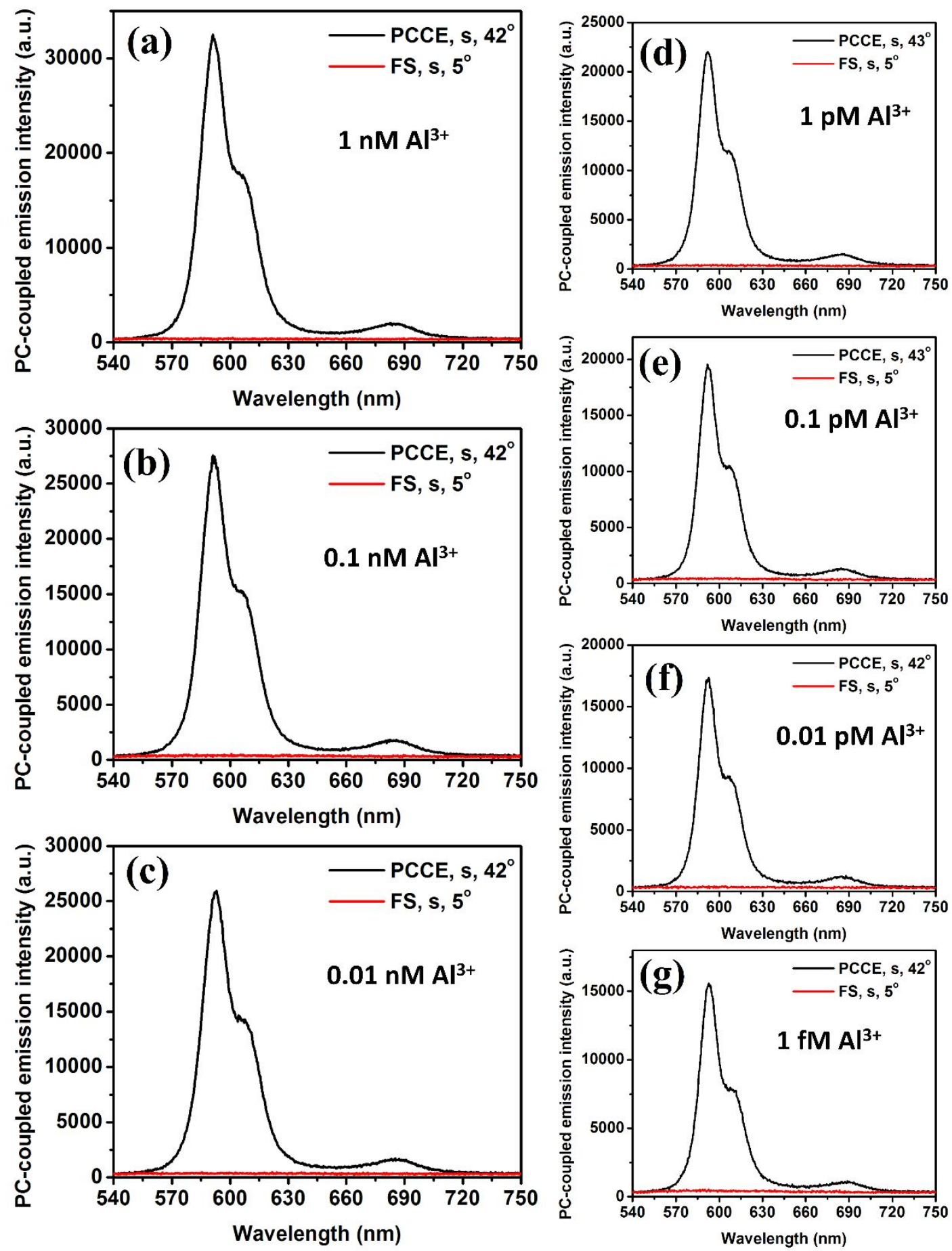
Figure S11. PCCE spectra for (a) $1 \mathrm{nM}$, (b) $0.1 \mathrm{nM}$, (c) $0.01 \mathrm{nM}$, (d) $1 \mathrm{pM}$, (e) $0.1 \mathrm{pM}$, (f) $0.01 \mathrm{pM}$ and (g) $1 \mathrm{fM}$ concentrations of $\mathrm{Al}^{3+}$ ions with $1 \mathrm{mM} A R S$ and AgNPs. Experiments were performed $532 \mathrm{~nm}$ laser excitation and $60 \mathrm{~nm} P V A$ dielectric in cavity configuration. The plots indicate the PCCE spectra along with their respective FS spectra. The collection angles are also mentioned. In the angular sweep from $0^{\circ}$ to $90^{\circ}$ degrees, the angle showing maximum emission intensity counts is chosen for each of the cases above.
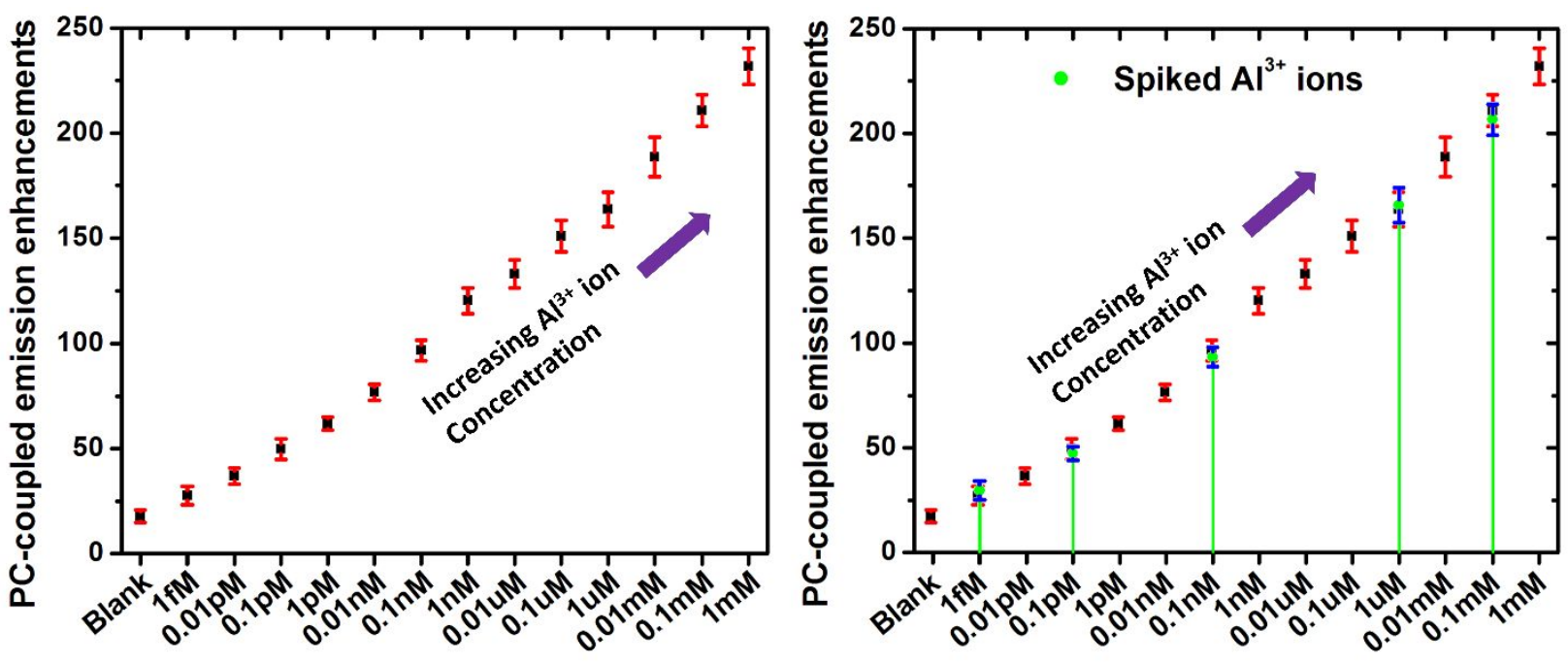

Figure S12. (a) PCCE enhancements obtained with different concentrations of $\mathrm{Al}^{3+}$ ions from $1 \mathrm{mM}$ to 1 $f M$ with 10 times dilution, with the use of $1 \mathrm{mM}$ ARS in 60nm PVA matrix. Blank indicates 17 -fold enhancements obtained with ARS and AgNPs. (b) Overlap of emission enhancements obtained with that from (a) and from spiking experiments (green color dots shown with green lines connecting them to corresponding $\mathrm{Al}^{3+}$ ions concentration in $x$-axis for ease of understanding). For spiking studies $0.01 \mathrm{mM}$, $1 \mu M, 0.1 \mathrm{nM}, 0.1 \mathrm{pM}$ and $1 \mathrm{fM}$ concentrations were chosen. 

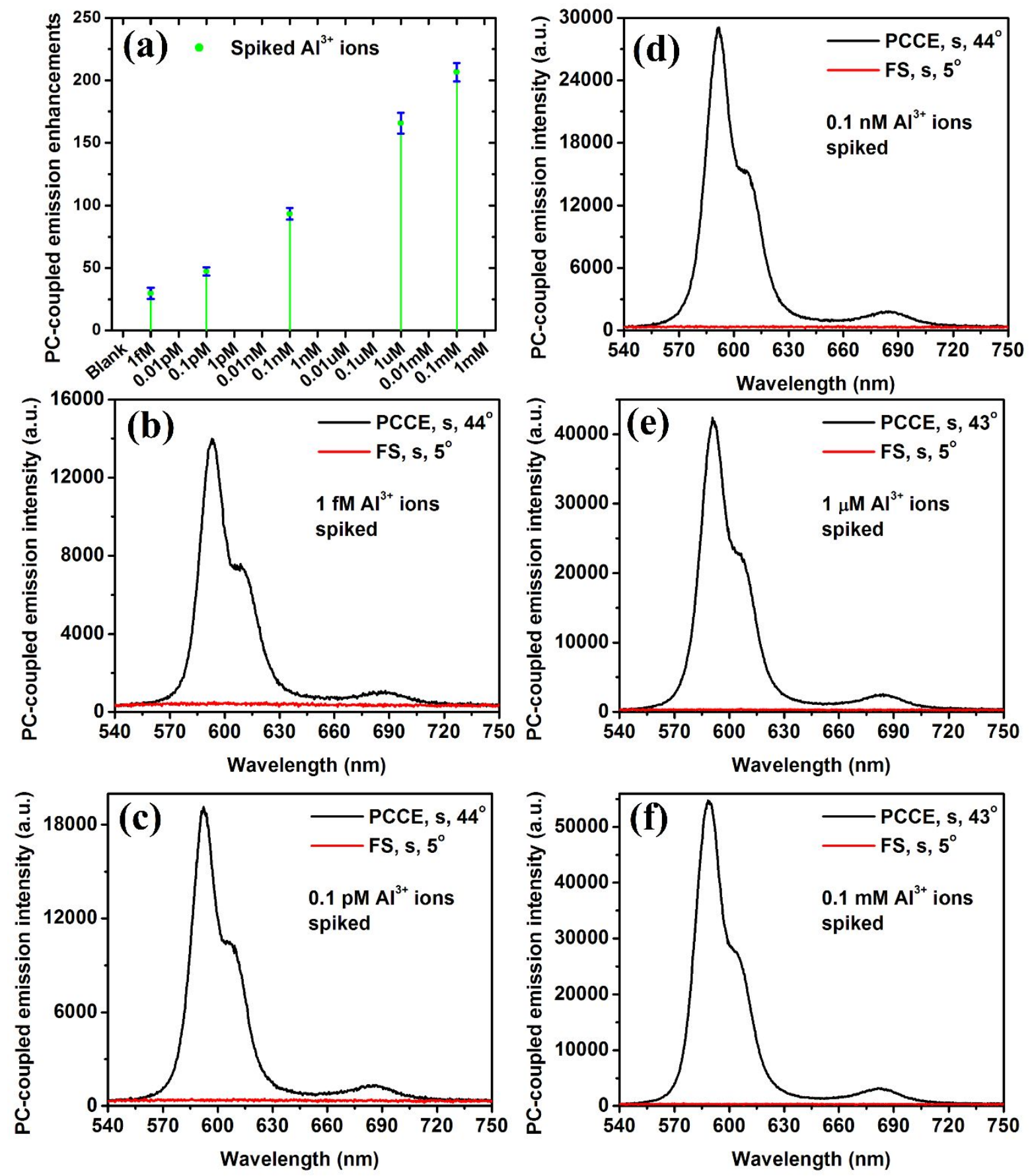

Figure S13. (a) Shows the PCCE enhancements obtained from spiking experimental results (green color dots shown with green lines connecting them to corresponding $\mathrm{Al}^{3+}$ ions concentration in $x$-axis for ease of understanding). (b), (c), (d), (e) and (f) are the PCCE spectra along with corresponding FS values for spiking studies with $0.01 \mathrm{mM}, 1 \mu \mathrm{M}, 0.1 \mathrm{nM}, 0.1 \mathrm{pM}$ and $1 \mathrm{fM}$ concentrations. 


\section{Percentage recovery studies:}

A standard solution of $0.01 \mathrm{pM} \mathrm{Al}{ }^{3+}$ ions was prepared in drinking water sample. The percentage recovery was determined by spiking this standard solution of $0.01 \mathrm{pM} \mathrm{Al}^{3+}$ ions with different concentrations of $\mathrm{Al}^{3+}$ ions ( $1 \mathrm{pM}, 0.1 \mathrm{nM}, 0.01 \mu \mathrm{M}, 1 \mu \mathrm{M}$ and $\left.0.1 \mathrm{mM}\right)$ as shown in the table $\mathrm{S} 2$.

Table S2: Determination of percentage recovery

\begin{tabular}{|l|l|l|l|l|l|}
\hline $\begin{array}{l}\text { Sample } \\
\text { number }\end{array}$ & $\begin{array}{l}\text { Concentration of } \\
\mathrm{Al}^{3+} \text { ions added }\end{array}$ & $\begin{array}{l}\text { Enhancements } \\
\text { expected }\end{array}$ & $\begin{array}{l}\text { Enhancements } \\
\text { obtained }\end{array}$ & $\begin{array}{l}\text { Percentage } \\
\text { recovery }\end{array}$ & $\begin{array}{l}\text { RSD (\%, } \\
\mathrm{n}=3)\end{array}$ \\
\hline 1 & $1 \mathrm{pM}$ & 98 & 93 & 94.8 & 2.7 \\
\hline 2 & $0.1 \mathrm{nM}$ & 133 & 125 & 93.9 & 3.0 \\
\hline 3 & $0.01 \mu \mathrm{M}$ & 170 & 167 & 98.2 & 1.7 \\
\hline 4 & $1 \mu \mathrm{M}$ & 200 & 192 & 96.0 & 2.8 \\
\hline 5 & $0.1 \mathrm{mM}$ & 247 & 240 & 97.1 & 1.2 \\
\hline
\end{tabular}

The emission enhancements are given as the average obtained from triplicate PCCE measurements $(\mathrm{n}=$ 3); RSD = Relative standard deviation. 